\title{
Global Perspectives on Work-Based Learning Initiatives
}

Jon Talbot

University of Chester, UK 
Published in the United States of America by

IGI Global

Information Science Reference (an imprint of IGI Global)

701 E. Chocolate Avenue

Hershey PA, USA 17033

Tel: $717-533-8845$

Fax: 717-533-8661

E-mail: cust@igi-global.com

Web site: http://www.igi-global.com

Copyright ( $\odot 2019$ by IGI Global. All rights reserved. No part of this publication may be reproduced, stored or distributed in any form or by any means, electronic or mechanical, including photocopying, without written permission from the publisher.

Product or company names used in this set are for identification purposes only. Inclusion of the names of the products or companies does not indicate a claim of ownership by IGI Global of the trademark or registered trademark.

\section{Library of Congress Cataloging-in-Publication Data}

Names: Talbot, Jon, editor.

Title: Global perspectives on work-based learning initiatives / Jon Talbot, editor.

Description: Hershey, PA : Information Science Reference, 2019. I Includes

bibliographical references.

Identifiers: LCCN 2018010708| ISBN 9781522569770 (hardcover) | ISBN

9781522569787 (ebook)

Subjects: LCSH: Education, Cooperative--Case studies. I Experiential

learning--Case studies. I School-to-work transition--Case studies.

Classification: LCC LC1049 .G56 2019 I DDC 371.2/27--dc23 LC record available at https://lccn. loc.gov/2018010708

This book is published in the IGI Global book series Advances in Educational Technologies and Instructional Design (AETID) (ISSN: 2326-8905; eISSN: 2326-8913)

British Cataloguing in Publication Data

A Cataloguing in Publication record for this book is available from the British Library.

All work contributed to this book is new, previously-unpublished material.

The views expressed in this book are those of the authors, but not necessarily of the publisher.

For electronic access to this publication, please contact: eresources@igi-global.com. 


\title{
Chapter 11 \\ Work-Based Learning in the United Kingdom: What We Know of Practice and an Example - The WBL Module and WBIS Program at the University of Chester
}

\author{
Jon Talbot \\ University of Chester, $U K$
}

\begin{abstract}
The term work-based learning has been widely used in higher education in the UK since the 1990s, and there is evidence of a spread in practice. However, it is not recognized as a subject by the UK Higher Education Statistics Authority so that the extent of practice is unknown. A small unpublished survey sheds some light on the varieties and extent of practice in England and Wales, identifying five different approaches. Different pedagogical practices can exist within single universities, and most of the chapter outlines how the University of Chester incorporates two practices. Its work-based learning (WBL) module is available for all full-time second-year undergraduates regardless of discipline. Its purpose is to enable all students of the university the opportunity to gain real-world workplace experience and sensitize them to the requirements of experiential and lifelong learning. By contrast the work-based and integrative studies (WBIS) is an example of a fully negotiated whole program designed to facilitate the development of practice for those already working.
\end{abstract}




\section{INTRODUCTION}

'Work based learning' has wide currency as a termin UKeducation, both in universities and sub-degree vocational colleges. This chapter concentrates upon its use and application in universities and in particular a case study of the WBIS program at the University of Chester. Although the term itself is widely used to describe courses and modules it is not a 'subject' as recognised by the Higher Education Statistics Authority (HESA) so there is standard definition as to what the term means and no data on how many students are engaged in it. Casual observation confirms it is predominantly located in teaching intensive universities with rather less in those whose institutional mission is directed towards research. It also appears to be located in particular vocational disciplines such as health and engineering. A number of universities, including Chester have non-disciplinary Work based learning centers or units. Estimating the number of students who are engaged in something which might be called Work based learning is fraught but it would appear the numbers are rising.

The origins of practice can be traced back to the late 1960s and early 1970s when there were the first attempts to introduce whole program learning by contracts. The earliest example of such a program in the UK is the Independent Study program developed in the former North East London Polytechnic from 1974 (O'Reilly 1989). The program was conceived as being as being cross curricular and cross faculty. Students negotiated their award rather than choosing from a pre-set list of modules. The program also pioneered the use of short awards and ran successfully for a number of years especially with mature, adult learners so that by the end of the 1980s it accounted for $10 \%$ of the entire student body. The learning contract entered into by students began with a consideration of past learning as the basis for making a claim for academic credit, a review of current learning, a consideration as to what the student wished to learn, followed by how they would achieve this, what was needed in terms of resources and how the student would demonstrate they had achieved their aims. The proposed contract was then scrutinised by a team of tutors and a personal academic tutor allocated (O'Reilly 1989, p. 48). The other element established in the programme was to make "critical reflection an explicit element of the learning process' (p. 50). Although attracting the program was criticised in an external government report in 1990 and administrative problems led to its closure. Many of the practices pioneered at North London Polytechnic were incorporated into the Work Based Learning framework by Middlesex University in 1995, which remains a leading provider and a template for other institutions (Portwood \& Garnett, 2000; Lester \& Costley, 2010). 
In contrast to the framework at North London Polytechnic the frameworks developed for Work based learning at Middlesex and other universities is not constrained by the requirement to utilise subject discipline modules. Instead the negotiated curriculum is determined by the needs of the workplace which are practice based and hence trans-disciplinary (Nixon, Smith, Stafford, \& Camm, 2006). Such curricula are referred to 'shell frameworks', since they do not presuppose a subject discipline but instead enable the student to negotiate content (Talbot, 2017a). At one level, this is part of a broader objective which aims to engage an increasing section of the population in continuing lifelong learning - that is, continuing formal learning through-out a person's life rather than ending at some predetermined point (Field, 2006). The development of work based learning programmes for adults also reflects a deeper understanding of the ways in which learning occurs in the workplace (Malloch, Cairns, Evans \& O'Connor, 2013; Illeris, 2011), and an attempt to extend the mission of universities beyond the traditional teaching of full-time undergraduates and carrying out research. In order to meet the learning needs of adults, many of the fundamental assumptions of traditional education and delivery models have had to be rethought. These include assumptions about the nature of knowledge and the mechanisms for learning. In addition to these academic issues have come a series of institutional, administrative and cultural challenge as are outlined in the example of Chester.

\section{WORK BASED LEARNING IN ENGLAND AND WALES}

The spread of Work based learning in British universities is in urgent need of greater research. One of the few studies comparing Work based learning pedagogic practices noted that many are largely cohort-based, involve didactic instruction in subject disciplines and are delivered to paying organizations (Nottingham, 2012). But beyond that there is very little. A little more light can be spread on the situation by reporting some of the unpublished results from a survey undertaken in 2015 by the author. The data is taken from a study designed to establish the extent to which the accessing of freely available learning materials from MOOCs is being used to make claims for prior learning in work based learning departments. Forty one of the 137 universities in England and Wales were contacted, where there was some reported Work based learning, of which twenty six responded (Talbot 2017b). Of As part of the study participating departments were asked to describe the activities they engaged in under the term 'Work based learning'. The results are reported in Figure 1 (below). 
Figure 1. The varieties of Work based learning practices in England and Wales (2015) by university $(n=26)$

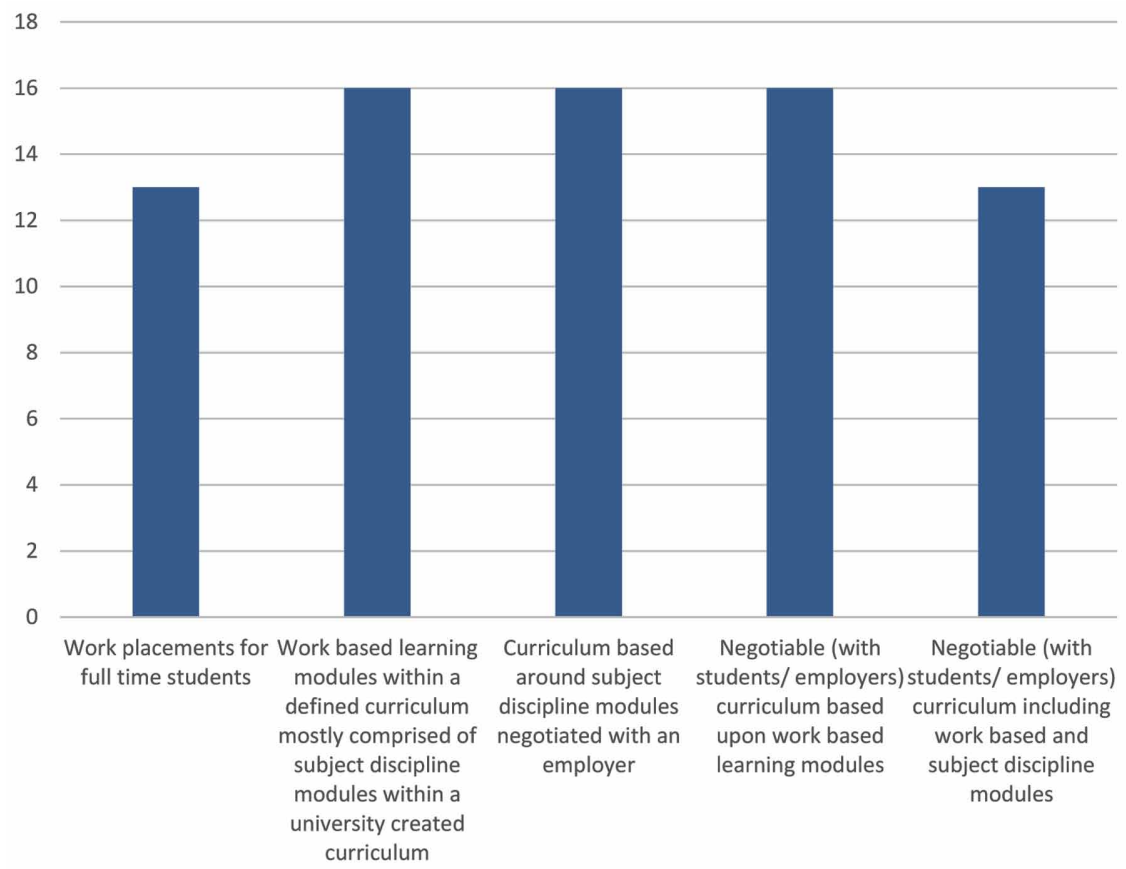

What the survey reveals is a multitude of practices. In some instances Work based learning is regarded as a term to describe work placements for full time students- a definition consistent with practices described elsewhere in this book. For three of the universities that is the only form of Work based learning engaged in. By contrast in 12 other universities there are no placements for full time students so that their provision is entirely for part time, adult learners. Excluding those who simply offer work placements on an otherwise conventional full time program of study, only two universities offer no negotiated programs with employers and/ or individuals, indicating in most Work based learning departments there is flexibility in curriculum design. The majority of universities offering negotiated programmes are willing to include work based and subject discipline modules in the curriculum. However for four universities Work based learning is a program of learning negotiated with employers and/or individuals comprised entirely of work based (ie. experiential) modules with no named subject discipline modules. The majority of universities provide Work based learning in more than category although only four make provision in all categories. Within this general pattern there are some individual variations. 
In one university Work based learning is only offered as a 'top up' to complete the final level of a degree whilst at another, students are able to negotiate assignments so that they are either 'work based' or 'traditional'.

A second question asked for the number of students engaged in Work based learning. The results are presented in Figure 2.

For this question respondents were asked to estimate the total number of Work based learning students at their university so the data here cannot be relied upon. The most significant finding is that 11 universities estimate they have over 1000 students. Nonetheless it is probably considerably more than many both inside and outside the field would expect and is an under-estimate since some of the main providers did not participate in the study, so it seems safe to assume there are over 10,000 students in England and Wales engaged in some form of WBL during 2015. This figure has to be interpreted with caution as at least some of those students will be engaged in full time study on an otherwise conventional programme. What can be said is that for an academic activity which did not exist twenty five years ago, WBL is becoming a significant element of British HE provision.

In summary there is no definitive data on the extent of Work based learning in British universities. The data presented here excludes Scotland and Northern Ireland and make no claim to be definitive for England and Wales. However it would seem there are significant numbers of part time, adult students who are now participating in some form of work based learning. It also seems there is a variety of pedagogic approaches involved.

Figure 2. Numbers of students engaged in Work based learning in England and Wales (2015) by university $(n=25)$

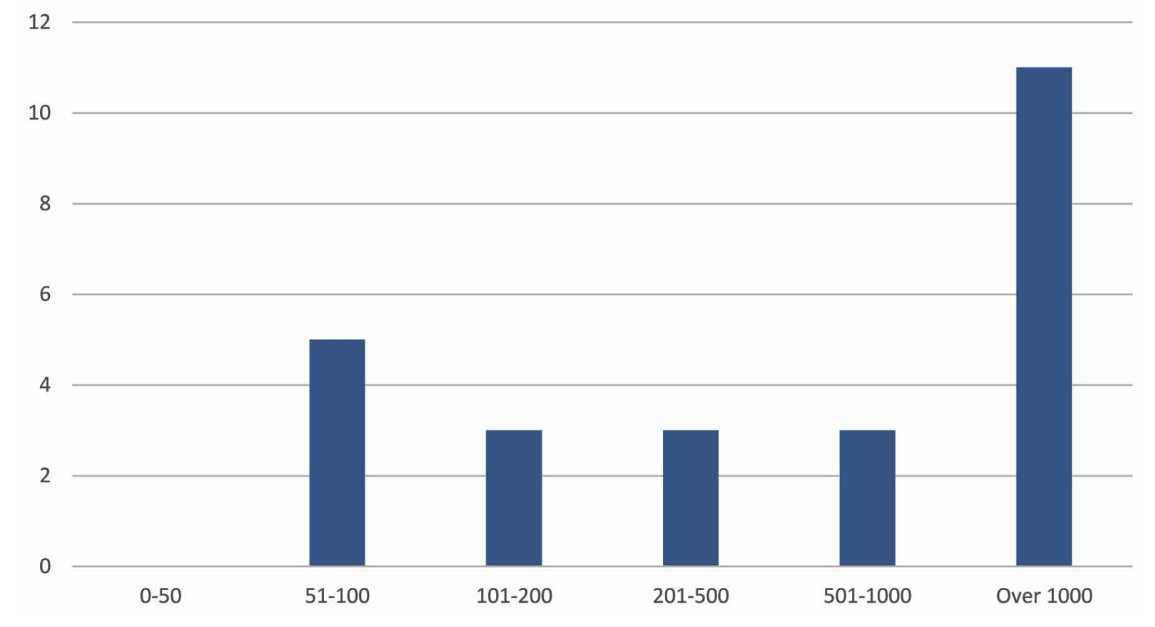




\section{The Development of Work-Based Learning at Chester}

It is thought the University of Chester in North West England is one of the largest providers of Work based learning in the UK both for its full time undergraduates and part time adult learners. The university, founded in 1839 as a theological and teaching college, is principally focused upon the teaching of full-time undergraduate students rather than being research oriented. Since the 1980-1981 academic year, all full-time undergraduates at Chester pursuing non-vocational degrees have undertaken some form of learning in the workplace as part of their studies. For the first decade, this was undertaken on a pass-fail basis, with no credits awarded. To expand this model, outside help was sought and a small government grant was awarded in 1990-1992, which drew upon the expertise of the Learning from Experience Trust ${ }^{1}$.

The trust was created and led by Norman Evans, a practitioner rather than a theorist, who did much to spread interest in the idea that learning occurs directly from experience in all spheres of life and not just in formal educational settings. $\mathrm{He}$ also believed such learning can be captured and translated into formal academic credit. The first cohort to receive academic credit for experiential learning in the workplace was in 1991, when 25 students completed this process, called the Work Based Learning (WBL) module. Since 1996, all second year students at Chester have been required to undertake some form of experiential learning with the majority opting for the WBL module. Some of the distinctive features of the WBL module is that it is aimed equally at students on vocational and non-vocational degrees and that students are not simply 'on placement' but are working. Each student is matched with an employer and given a job description. Assessment is principally the responsibility of the university ( $90 \%$ of the available marks), the rest by the employer. Assessment focusses upon the development, during the placement, of key employability skills in terms of the students' learning in that respect. They are also required to look forward to further development following the placement. The management of the module is a considerable administrative and academic enterprise with specialist advisors to ensure students are matched with suitable employers.

A second model of experiential workplace learning was developed in 1998, this time for adults in the workplace who did not attend the university. From the outset, the needs of part-time adult learners were recognized to be significantly different from full-time, younger undergraduates. The new framework, Work Based and Integrative Studies (WBIS), was created with the adult learners' specific requirements in mind. WBIS is an example of what is termed a work-based learning (WBL) "shell framework" - a validated degree that enables adult learners to negotiate an award title and program of learning tailored to their individual needs within the workplace (Talbot 2017). The main equivalent to WBIS in the U.K. is the Work Based Learning 
Framework at the University of Middlesex and the discontinued Learning through Work program at the University of Derby (Minton, 2007).

\section{Experiential Learning in the WBIS Program}

Academic pathways within WBIS are negotiated either for individual students or cohorts, as are award titles. Award titles also indicate a WBIS award; for example, a student may obtain a "Bachelor of Arts in Leadership in Health Services (WBIS)" or "Master of Arts in Urban Regeneration Practice (WBIS)." Learners, therefore, complete programs of study and receive award titles relevant to their practice requirements. Within their pro-grams of study, students are permitted to obtain academic credit for previous learning achievements, both for-mal (certificated) and informal (experiential). University regulations at Chester allow an award to be conferred where up to two-thirds of the credit requirement can be obtained through the accreditation of prior learning (APL) ${ }^{2}$. APL can be awarded in two ways. The first, accreditation of prior certificated learning (APCL), is permissible where a student has an existing current academic qualification (obtained within the previous five years) of the same level and in an area relevant to the planned WBIS award. Awarding credit in such circumstances is fairly straightforward, following checks on the veracity of the claim.

In other circumstances, the second way that students can make claims on the basis of experiential learning is through the accreditation of prior experiential learning (APEL). In turn, APEL claims can be made in three sets of circumstances. The first is when students hold a formal qualification that is not current; they can make a claim based upon a demonstration of how formal knowledge inherent in the qualification has been applied in practice. A second way of obtaining credit via an APEL claim is when a student holds an unaccredited qualification that nonetheless has content relevant to higher education, which might be the case with a qualification provided by a corporation. The third way is when a student has no existing qualification but has a wealth of practical experience to draw upon, which lends itself to higher-level study and analysis.

In each of the examples cited above, an award of credit is made after the student provides evidence of the basis for their claim, accompanied by a reflective review for up to half the word count for an assignment for the volume of credit sought. In other words, Chester utilizes a "developmental" approach to the awarding of credit for past learning rather than a simple "credit exchange" (Butterworth, 1992). For example, an APEL claim for 40 credits (20 credits ECTS [European Credit Transfer and Accumulation System]) would involve the writing of a reflective review of up to 5,000 to 6,000 words - half that for the award of credit for new learning ${ }^{3}$. The reflective review itself must follow generic-level descriptors for the award and demonstrate 
familiarity with and the application of relevant academic literature. The reflective reviews follow a prescribed format in which the basis for the claim is described and the experience is analyzed with reference to leading, authoritative academic and professional literature as the basis for reflective thinking about planned future actions. As with any claims for past experiential learning, an academic judgment has to be made on the volume of experiential learning the student has so that it can be translated into an appropriate award of academic credit. As a rule of thumb, the more experienced a student is and the greater the level of responsibility they have in the workplace, the greater potential for making an APEL claim. Claims based purely upon experience require students to submit a portfolio of evidence bound together with the reflective review of that experience. When assessing such submissions, tutors concentrate on the reflective review, as this represents the learning from experience rather than the content of the portfolio, which is present mainly for verification and reference. Assessment for claims of experiential learning on past actions is on a pass-fail basis only.

In addition to awarding credit for past experiential learning, WBIS also allows students to obtain credit for new, purpose-designed experiential learning in either single, double or triple modules, known as "Negotiated Experiential Learning Modules" (NELMs). With the help of tutors, students identify workplace projects for a specific volume of credit and are then assessed. Specific learning outcomes, intended outcomes, learning re-sources and so on are therefore negotiated with the student using a standard template - a Negotiated Experiential Learning Agreement (NELA) adapted for the specific project. As part of their assignment, especially for larger 60 credit NELMs, students are encouraged to produce workplace artefacts, typically reports, as the basis for action. These can be submitted as part of the word count but are not assessed by tutors. As products of practice knowledge, the value of the workplace artefacts is assessed by practitioners rather than academics. The submitted reflective review on the project will include a description of the project, an analysis informed by the relevant literature and a summary of the learning that is the basis for actions in the future. As with all other assignments, standard academic conventions on referencing and other matters are expected. The assessment of new experiential learning is graded in the same way as any other module.

The use of experiential learning in WBIS constitutes the "Work Based" part of the title of the program. Although experiential learning forms the bedrock of WBIS, it has always been recognized that experiential learning alone does not always meet the learning needs of students. Students are, therefore, able to study traditional subject disciplines where these are relevant to their needs, such as project management, leadership, finance and any other number of specialist subject requirements. When they do so, learning is often informed by their own experiences. For example, assignments for subject modules such as project management will often 
incorporate the students' experiential learning. The combination of knowing from experience with more formal varieties of knowledge is what explains the reference to "integration" in the WBIS title. Although essentially an experiential learning program, it is integrated with more formal ways of knowing. An important aspect of the distinctive pedagogy of WBIS is the dialogue between the real, lived experience of students and abstracted conceptions of the world.

\section{FACILITATING LEARNING IN WBIS}

The WBIS tutors have always believed that for students to analyze their experiences solely on untutored introspection is not enough. Students also are required to read relevant literature as in any other university pro-gram. The difficulty is that unlike a subject-discipline approach where it is possible for a tutor to provide a standard reading list for all students, the individualized, contextualized and situated approach in WBIS means that no experiential learning module begins with a set reading list. In workplace projects, there are often issues related to organizational design, culture, leadership and so on, but precisely knowing where the boundaries are is difficult to conceive. In addition to standard academic sources, students may refer to internal organizational documents, those produced by professional and trade bodies, government and so on. There may be other sources of information that are entirely practice-based and tacit, but also are important. Facilitating learning, therefore, requires both highly skilled tutoring and a willingness on the part of students to develop an ability to teach themselves and to become autonomous learners. To assist with this, students are allocated to tutors with relevant specialist knowledge. The program also incorporates modules at the outset of the program, which are designed to sensitize students to their learning needs and preferences, their academic skills and the ability to learn reflectively.

Accompanying this pedagogic method has been a commitment to placing the needs of the learner before administrative convenience wherever possible. WBIS students can register and complete their studies flexibly within guidelines designed to ensure progression. They are able to complete short awards (for example, a professional certificate or diploma) that they can, if they wish, build up into bachelor's and master's awards (a full award). Payment is flexible so that students can progress on a pay-per-module basis if they wish. As a result of these practices and curricula tailored to their needs, WBIS has, without any significant help from the rest of the university, managed to increase its student numbers by approximately 20 percent every year since 1998 and continues to grow even in the current financially difficult climate. Over time, the practice has spread into other parts of the university, so that many WBIS pathways, and hence students, are located in other faculties. 
The rest of this paper describes how the program operates and assesses some of the difficulties integrating a radical program within a conventional university setting.

\section{The WBIS Program: Summary of the Principal Features}

The five key features of WBIS are flexibility, learner focus, negotiability, autonomous learning and application. Flexibility is manifest in the ability of students to begin and progress study at times convenient to them, within the overall framework of the university's regulations for progression and completion. Flexibility also is evident in enabling students to progress on a "pay-per-module" basis and work at times and places convenient to them. Flexibility in learning enables students to incorporate workplace learning into their accredited program of study, change their program where circumstances change and so on.

Closely allied to the notion of flexibility is the focus on learners and autonomous learning. As the starting point in WBIS, no assumptions are made about curriculum and subject or the needs of the learner. Therefore, there is no timetable of lectures or day release from one's workplace; instead there is a program of workplace workshops, individually negotiated tutorials, and e-learning. Students are able to determine the focus of their learning and are free to incorporate transdisciplinary experiential learning as well as more traditional subject-based modules into their program. The emphasis on individualized learning requires students to accept far greater responsibility for their learning than in conventional, essentially didactic programs, and to develop the necessary ability to learn in this way at the outset of the program.

WBIS students negotiate their award title and program of learning within the WBIS framework (referred to as their "learning pathway"), whether as an individual or part of a cohort. This enables the precise tailoring of learning to student needs. The starting point in WBIS is the individual or cohort, not subject discipline. Be-cause all awards exist within the WBIS framework, it is possible for students to negotiate their award title and learning pathway, which must be congruent, without the need for a revalidation. Students can register for short awards such as a professional certificate (30 ECTS credits at levels 4,5 and 6) and stack credits progressively. Many students only require such short awards; for example, a popular award is the postgraduate certificate (30 ECTS credits at level 7). Many midcareer professionals find themselves assuming managerial responsibilities, yet have no formal management qualifications, and this short award helps to provide just that. Another example is that the university has developed a postgraduate certificate for those in higher education who wish to facilitate WBL and require some formal learning in the area. WBIS awards are available at all levels in higher education, from National Qualifications 
Framework (NQF) 3 levels 4 to 7. A separate program enables senior practitioners to obtain a transdisciplinary professional doctorate.

The final important feature of WBIS is application. Assignments, as long as they meet the learning outcomes, are negotiable based upon generic examples relevant to the level of learning. The aim is to create learning out-comes that are integrated with workplace practice. They are either work-based ("I have done/am doing something and wish to study it formally") or work-related ("I need to study something formally, I intend to do something and it will be useful to develop more contextual knowledge about what I do"). Assignments can be based around projects in the workplace, therefore transdisciplinary, or involve reflective learning in a particular subject, such as project management. A typical work-based WBIS module involves the student reflecting upon experience of doing by reading authoritative literature. The reflective process is designed to enable the individual to alter practice in response to informed, reflective thinking. The purpose of assignments is there-fore not to impart disembodied, universal knowledge but to generate situated knowledge as the basis for

action. Unlike conventional programs where students demonstrate their knowing, WBIS students also are expected to demonstrate how knowing leads to change and doing. We like to say WBIS students "generate knowledge at the point of consumption."

\section{WBIS in Practice: Devising Learner Pathways and Tutor Roles}

At the start of the WBIS process, students are allocated a personal academic tutor (PAT) who guides them through the process. Most students complete a module entitled "Self-Review and Negotiation of Learning." The module requires the student to review their personal development to date, their current workplace role, and from this, develop a rationale for their intended learning pathway and award title. This is formally recorded and assessed for relevance, accuracy and coherence by the whole program team. At this stage consideration is given as to whether the student is able to make any claims for prior learning. University regulations enable a named award to comprise of up to two-thirds of total credits for the accreditation of prior certificated learning (APCL) or the accreditation of prior experiential learning (APEL) as previously described.

As part of the same module, students are introduced to the idea of reflective learning and undertake a reflective review, usually of some sort of critical incident. The choice of modules students complete on their learning pathway is virtually limitless and is only really bound by the ability of the university to provide underpinning subject expertise. Students can complete current experiential learning modules on workplace projects, as previously described, either as single, double or triple modules using customized learning outcomes and module descriptors. Alternatively, students 
can study some of the many modules WBIS tutors have developed over the years in response to demand; or they can study any accredited module at the university, provided it is at the appropriate level; or students can study new modules, which can be accredited as need arises.

Because of the need to develop modules for clients, the university has created a committee to scrutinize the accreditation of new modules called the "WBIS Approval Panel." The panel has scheduled monthly meetings and is comprised of senior members of the university and quality assurance specialists. The panel scrutinizes and approves new modules and pathways specifically created for employers in co-delivery arrangements. Over the course of time, there have been a large number of accredited WBIS modules developed. WBIS students are therefore presented with an almost limitless menu of learning options. They can make APL claims for credit; they can negotiate and complete experiential modules based upon workplace projects; and they can complete generic WBIS modules, such as "project management" or ones developed specifically for their own needs or other clients such as the Foundation for Government program developed for the U.K. government with a strong emphasis on vocational learning. In addition, they can study modules elsewhere in the university, provided that these are cognate and at the appropriate level. If none of these options suit the student, new modules can be delivered that are precisely tailored to their needs.

Most WBIS students begin their studies with the Self-Review module, and at this point, students negotiate their program with their tutor. The negotiation involves selecting appropriate modules, the order in which they will be studied, submission dates and their qualification title. The choice is not arbitrary, but is on the basis of a reasoned self-analysis of learning achievements and requirements. As part of the process, students complete what is known as an approved studies learning agreement (ASLA), which is a type of learning contract. The ASLA indicates what the student will study and when and, following independent scrutiny by all WBIS tutors, is sent to the registry function of the university. The ASLA indicates how many credits of APL will be claimed and the balance of negotiated experiential learning modules and/or other modules. Students registering for a bachelor's degree are only required to indicate their pathway for one level at a time, not all three. The ASLA also includes planned submission dates.

Learner autonomy is facilitated by a variety of mechanisms. Students are inducted to prepare them for independent study and are able to call upon the services of a dedicated distance librarian. In addition to individual tutor support, specialist modules have been developed that focus on the development of learning skills, such as Skills and Approaches for Work Based Learning. Another mechanism is e-learning, used increasingly in re-cent years, to meet employer expectations (Brown, Murphy, $\&$ Wade, 2006). Individual modules are widely supported by dedicated learning 
materials hosted on a collective e-learning platform called the "WBIS Portal." Tutors recognize that e-learning alone rarely suits the learning preferences of students (Singh, 2003; Welsh, Wanberg, Brown, \& Simmering, 2003; Graff, 2006; Hughes, 2007), so it is usually blended with personal tutorials and workshops. Another important component of the WBIS pedagogic method is the use of formative assessment for all assignments, so that the production of assignments also is a negotiated process (Nicol \& Macfarlane-Dick, 2006). Students are encouraged to submit plans for their work, as well as full drafts, prior to formal submission, upon which they receive tutor comments within two weeks. Formative assessment usually includes full assignment comments and line-by-line comment boxes. Grammatical irregularities also are high-lighted. Tutors have received training in learning disability awareness and full institutional support is available where such disabilities are suspected.

The emphasis on individualized, autonomous learning enables the student to receive more tailored tutor sup-port than is available on most programs. The ability of students to learn autonomously is progressive, so for the most part, they become more proficient as they proceed through their studies. As with any program, student support requirements vary across individuals, so tutor support, like the program itself, is tailored to individual requirements. Invariably, progression rates vary between individuals. In some cases, this is to do with life events and circumstances such as a change in job, moving house and so on. But the inherent flexibility in WBIS reveals differing levels of motivation to learn between individuals. Student progression-the rate at which they accumulate credit - is a source of constant debate among tutors. In the past, tutor attitudes were more relaxed than they are now. Students have target submission dates on a quarterly basis and are expected to submit a minimum of 60 credits (30 credits ECTS) per calendar year. Monitoring of student progression also is administratively complex, but persistent non-submission results in termination of studies, following suitable warnings.

The emphasis on individual tuition and associated practices such as formative assessment may make it appear that WBIS is a relatively costly, and therefore an inefficient delivery mechanism. In the past, this has been a perception elsewhere in the university, but this is not borne out by the facts; staff/student ratios are higher than on most academic programs. In part, the reason for this is a product of the method. WBIS students typically require far greater input at the beginning of the program than they do at the end. As they learn to become autonomous learners, the need for active tutor input declines. Adult learners engaged in meaningful study are on the whole well motivated to do so. Efficiency in terms of the use of tutor time also is improved where delivery and assessment is carried out by a co-delivery partner. 


\section{Quality Assurance}

As with any other academic program, quality assurance (QA) is fundamental for the delivery of WBIS. In this sense, QA is not simply something imposed externally or from within the institution. WBIS is the creation of academic tutor practitioners prepared to place the learning needs of students over the traditional academic allegiance to instruction in subject discipline. It is not the product of an institutional drive to generate additional income, although as is discussed in the next section, "WBIS as a Business," the learning and business aspects of WBIS go hand in hand. As a result, the commitment to the maintenance of academic quality is integral to the culture and practice of those delivering it. The role of external and internal QA agencies has, therefore, less to do with the external imposition of an artificial concept of academic quality (as much of the academic literature implies), but to assure and verify its presence.

Such quality assurance is not always apparent to those, especially in the rest of the university, for whom any-thing as nonstandard as WBIS represents the risk of reputational damage. As Gibbs (2009) has noted in the context of WBL at the University of Middlesex, to provide direct empirical evidence on academic standards is very difficult, and in every university where WBL has developed, there has been a large degree of institutional resistance based upon a fear of low academic standards. At Chester, the radical nature of WBIS has created a distinctive community of practice that is acutely aware of the anxieties of the rest of the university in this respect (Leonard \& Talbot, 2009). The explicit focus on learning, rather than subject discipline and didactic instruction, is deeply embedded within the community. The latest developments in learning theory, academic standards, credit systems and level descriptors are the stuff of everyday conversation, as well as more formal meetings held once a month to discuss learning and teaching issues. The cultural commitment to quality is embedded in a formal QA system.

Within the U.K., there are standard external and internal quality assurance processes and procedures, which, although often bureaucratically burdensome, have the virtue of signalling to others that academic standards are not only maintained, but there are constant attempts to improve upon them. On a day-to-day basis, there are regular formally constituted and recorded program team meetings at which quality issues are discussed and resolved. Reporting directly to these meetings are those who have previously met with student representatives. The outcomes of both sets of meetings, along with other materials such as student evaluations of modules, are reported in an annual monitoring report prepared by the program leader, and independently evaluated by an-other academic member of the faculty, before discussion occurs at the faculty level and, where there are out-standing issues, at the university level. The standard of academic work is independently reviewed by an external examiner, an 
academic from another university. The external examiner attends assessment and academic award boards, where marks and final evaluations are formally decided, and prepares a formal written report on the work reviewed. Minor reviews to the program can be made, but every five years there is a formal re-revalidation, again involving external independent academic advisors.

In addition to internal quality assurance, all U.K. universities and their individual programs are regulated and overseen by the Quality Assurance Agency for Higher Education (QAA), an independent body charged with setting standards and ensuring delivery of those standards. The QAA set standards in broad terms by publishing subject benchmarks, defining the nature of the different degree programs. They also are responsible for inspecting and assuring academic institutions. The last inspection at Chester was in 2010, where special attention was paid to WBIS as an example of nonstandard provision. The review included interviews with staff and students, a review of policies, practices and procedures, and sampling of student assignments. The final review identified WBIS as an example of good practice (Quality Assurance Agency for Higher Education, 2010, pp. 11, 20).

As well as regulatory regimes, there are a number of professional networks with which WBIS tutors engage. The Higher Education Academy (HEA) seeks to improve and maintain pedagogical practices of academics in higher education. All WBIS tutors are certified fellows of the HEA and there is active involvement in the HEA employer engagement network as the basis for continuing professional development. There also is participation in other bodies such as the Universities Association for Lifelong Learning (UALL) and the University Vocational Awards Council (UVAC).

\section{WBIS as a Business}

For many academics, the idea of education as a business is an anathema. For WBIS tutors, getting and keeping business clients is simply part of the job; it is not viewed as threatening standards, academic integrity or the learning of students. Clients are made aware that the university maintains rigorous academic standards from the outset, and that the clients are not "purchasing" qualifications. The attention to individual learning needs and the focus on progressive learning does not preclude failure for some. It is a fact of life that without clients, there are no students.

This entrepreneurial attitude has been part of the WBIS culture from the outset. WBIS is partly the product of developments in theories of knowledge and learning, but these coincided with greater political encouragement to facilitate formal learning in the workplace during the later 1990s (Callender, 1997; Department for Education and Employment, 1998; Eraut, Alderton, Cole, \& Senker, 1998; Sutherland, 1998). At the same time, U.K. universities were encouraged by government to develop a "third mission," with the advent of the Higher Education Reach-out to Business and 
the Community Fund (HEROBC), to become more entrepreneurial (Burton, 1998). In addition to generating income from teaching full-time undergraduates and research funding, universities were expected to generate revenue from other commercial activities. WBIS, although an income-generating activity for the university, was, as previously noted, a program conceived and developed by tutors with a commitment to learning and wider engagement with learning from formerly excluded groups. Its invention, coincident with the "third mission" agenda, ensured greater institutional support than might be expected for a radical learning framework.

The emphasis on business has therefore been embedded in the culture and practice of WBIS tutors from the outset. To some extent, this is by virtue of necessity. Since WBIS is not well understood in the wider university, there has been little institutional investment in its development, including marketing and promotion. Along with the monthly meetings to discuss learning and teaching issues, there is another meeting to discuss business issues. Tutors and administrators devise publicity material and follow up interest from potential clients. Occasionally, tenders are bid for but much business comes from "word-of-mouth," as WBIS students tell their friends and colleagues about the program. Given the lack of resources tutors have sought low cost, time-efficient methods to ensure there is time for actual delivery. In recent years, this has led to pioneering use (for academics) of social media. For example an approach was made via Linkedin by a film production company based in Hollywood wanting accreditation for their in-house training.

The drive for more efficient and profitable ways of working has led to other changes in practice. In the earlier period of WBIS, almost all delivery was by WBIS tutors to individuals and employer cohorts. In recent years, direct delivery has been increasingly undertaken by third parties in what are called "co-delivery" arrangements. This describes the practice of delivery and assessment, using the WBIS framework being conducted by training companies or those delivering training and developing within companies and colleges. In this kind of relationship, the role of the WBIS tutor is facilitation and quality assurance. The mechanisms in place to achieve this, especially in respect of quality assurance, are beyond the scope of this paper, but are described by Talbot, Perrin and Meakin (2014). A final point to note in respect of the business orientation of WBIS is the ability to adapt to changing market conditions. We have already noted the gradual re-orientation towards co-delivery over other forms of delivery, especially individual tuition. Other adaptations have been driven by external factors, of which two have been especially important. First the financial crisis since 2008 has led to greatly reduced public spending and hence public sector training budgets. The profile of WBIS students has therefore been realigned with significantly fewer students working in the public sector currently than was the case a decade ago. 
The second major change is of more recent origin. In 2013 a pathway was created for graduates- The Chester Business Masters program. Graduates with first class degrees were offered a work placement and the opportunity to combine the placement with further study. Since 2016 this program has been superseded by a similar program as part of the UK government's Apprenticeship and scheme (Rowe, Perrin and Wall 2016). The distinctive feature of both programs from the perspective of WBIS is that both are aimed at younger people rather than more experienced practitioners. There is state funding to underpin the Apprenticeship program, making it attractive to the university. Being pre-validated, the WBIS framework makes it relatively easy to develop new pathways as opportunities arise.

\section{Integrating WBIS With the University}

WBIS produces a myriad of pathways for learners and cohorts. Some of these learning pathways are relatively prescribed such as the foundation in government developed for the British civil service or the GROW (Graduate Research Opportunities Worldwide) program developed for a group of Danish hoteliers, the first time a WBIS pathway was delivered in another language. Some pathways have been created for occupational groups such as regeneration professionals and housing managers. Most of the delivery has been from the Centre for Work Related Studies (CWRS) where WBIS is housed, but the framework belongs to the university as a whole, not one faculty. Increasingly, other members of the university have seen the opportunity WBIS represents and there are now many WBIS pathways delivered across the university, similar to the way Rogers (2003) suggested that the diffusion model illustrates the spread of innovations.

As might be expected, alongside the university's "friends of WBIS," there have been internal critics, usually based upon a perception of risk and lower standards. Universities are in many ways highly conservative institutions, and it is interesting to note that many previous attempts to create innovative learning models have failed to integrate with the existing academic infrastructure (Conole, 2004). In the past in the U.K., resistance to vocational education in universities led to the creation of polytechnics, while the failure to provide effective distance learning led to the creation of the Open University (Perry, 1976; Caley, 2001, Robinson 2007). Despite its growth, WBIS as in other universities, has encountered serious institutional resistance in many established universities amid fears that it represents a threat to academic standards (Garnett, 2007).

Experience at Chester suggests that in addition to academic objections, accommodating a non-standard program from an administrative perspective is equally problematic. The rolling admissions and negotiable aspects of the program have been a challenge for administrators used to enrolling school leavers once a 
year in named subjects with a specific set of familiar sounding modules. As can be imagined, the administration of WBIS is considerably more complex and, as a result, has necessitated having operational staff who work closely with and are themselves WBIS specialists, creating a kind of university within a university. While the emphasis in this chapter is necessarily focused on academic matters, implementing WBIS involves considerable operational challenges.

\section{CONCLUSION}

British universities are by tradition and practice highly autonomous and it appears that without any political encouragement many have developed Work based learning programs and modules in response to perceived need or demand. In part this seems to be part of broader attempts to make the curriculum both more flexible and more responsive to the requirements of the labor market and workplace. Practice in the case study portrayed here has been driven entirely by internal actors rather than as a result of government policy. Some state funded assistance was provided many years ago but this is a small part of the story.

What is lacking is any real empirical understanding of the scope and nature of practice across all universities. The fact that Work based learning is not recorded as a subject gives it a kind of official invisibility so that its undoubted rise has not only been unrecorded but largely unremarked upon. It would appear that the UK has seen significant developments in innovative practice and there have been attempts to transfer it to other European countries with it would seem, limited success (Schmidt 2006, WBLQUAL (undated)). While the introduction of work placements places relatively little stress on either educators or administrators, developing a flexible curriculum designed to meet the needs of adults in the workplace is far more challenging. Universities, to use Burns and Stalker's (1961) celebrated distinction, are essentially mechanistic organizations. They are adapted to stable operating conditions but are poorly equipped to deal with the rapidly changing learning requirements of a post-industrial, knowledge economy. WBIS is a program adapted specifically for the contemporary labor market, and those who work in higher education and appreciate the need to adapt may underestimate the difficulty of changing the faculty. The Frenchman Raymond Loewy (1951) cautioned that the most rational solutions to our problems are not necessarily the most appropriate. What is equally important is our readiness to accept those solutions. Although intended to be applied to the principles of industrial design, his concept of "MAYA" - Most Advanced Yet Acceptable - with the emphasis on "acceptable," is a useful starting point in considering how flexible Work based learning can be introduced. 


\section{REFERENCES}

Brown, L., Murphy, E., \& Wade, V. (2006, September). Corporate eLearning: Human resource development implications for large and small organizations. Human Resource Development International, 9(3), 415-427. doi:10.1080/13678860600893607

Burns, T., \& Stalker, G. (1961). The management of innovation. London, UK: Tavistock.

Burton, C. (1998). Creating entrepreneurial universities: Organizational pathways of transformation. Warrington, UK: Emerald Group Publishing Ltd.

Butterworth, C. (1992). More than one bite at the APEL. Journal of Further and Higher Education, 16(3), 39-51. doi:10.1080/0309877920160305

Caley, L. (2001). The possibilities in a traditional university. In D. Boud \& N. Solomon (Eds.), Work-based learning: A new higher education? Buckingham, UK: Open University Press.

Callender, C. (1997). Full and part time students in higher education: Their expressions and expectations. Na-tional Committee of Inquiry into Higher Education, Report 2. London, UK: HMSO.

Conole, G. (2004). The empire strikes back: Organisational culture as a facilitator/ inhibitor. In JISC infoNet (Ed.), When worlds collide: Changing cultures in 21st century education (pp. 27-34). Northumbria University. Retrieved from http://tools. jiscinfonet.ac.uk/downloads/publications/wwc.pdf

Department for Education and Employment (DfEE). (1998). The learning age: A new renaissance for a new Britain. Norwich, UK: HMSO.

Eraut, M., Alderton, J., Cole, G., \& Senker, P. (1998). Development of knowledge and skills in employment, Research Report 5. Brighton, UK: University of Sussex, Institute of Education.

Field, J. (2006). Lifelong learning and the new educational order (2nd ed.). Stokeon-Trent, UK: Trentham Books.

Garnett, J. (2007). Challenging the structural capital of the university to support work-based learning. In D. Young \& J. Garnett (Eds.), Work-based learning futures. Paper presented at the University Vocational Awards Council Annual Conference, Buxton, UK (pp.21-27). Bolton, UK: UVAC. Retrieved from http://www.uvac.ac.uk/ wp-content/uploads/2013/12/Work-based-Learning-Futures-FINAL.pdf 
Gibbs, P. (2009). Quality in work-based studies not lost, merely undiscovered. Quality in Higher Education, 15(2), 168-176. doi:10.1080/13538320902995782

Graff, M. (2006). The importance of online community in student academic performance. The Electronic Journal of e-Learning, 4(2), 127-132. Retrieved from http://www.ejel.org/volume4/issue2

Hughes, G. (2007). Using blended learning to increase learner support and improve retention. Teaching in Higher Education, 12(3), 349-363. doi:10.1080/13562510701278690

Illeris, K. (2011). The fundamentals of workplace learning: Understanding how people learning in working life. London, UK: Routledge.

Lester, S., \& Costley, C. (2010). Work-based learning at higher education level: Value, practice and critique. Studies in Higher Education, 35(5), 561-575. doi:10.1080/03075070903216635

Loewy, R. (1951). Never leave well enough alone. New York, NY: Simon and Schuster. Malloch, M., Cairns, L., Evans, K., \& O’Connor, B. N. (Eds.). (2011). The SAGE handbook of workplace learning. London, UK: Sage Publications.

Malloch, M., Cairns, L., Evans, K., \& O’Connor, N. (Eds.). (2013). The Sage handbook of workplace learning. London: Sage Publications.

Minton, A. (2007, July). Negotiation of learning contracts and assessment in work based learning. Paper presented at the Work Based Learning Network Annual Conference, University of Middlesex, London, UK.

Nicol, D., \& Macfarlane-Dick, D. (2006). Formative assessment and self-regulated learning: A model and seven principles of good feedback practice. Studies in Higher Education, 31(2), 199-218. doi:10.1080/03075070600572090

Nixon, I., Smith, K., Stafford, R., \& Camm, S. (2006). Work-based learning; Illuminating the higher education landscape. London, UK: The Higher Education Academy.

Nottingham, P. (2012). An exploration of how differing perspectives of work based learning within higher education influences the pedagogies adopted (Unpublished doctoral dissertation). Birkbeck, University of London, London, UK.

O'Reilly, D. (1989). Negotiating in an institutional context. In J. Stephenson \& M. Laycock (Eds.), Using learning contracts in higher education (pp. 46-54). London: Routledge. 
Perry, W. (1976). Open University: A personal account by the first vice-chancellor. Milton Keynes, UK: The Open University Press.

Pokorny, H. (2011). England: Accreditation of prior experiential learning (APEL) research in higher education. In J. Harris, M. Breier, \& C. Wihak (Eds.), Researching the recognition of prior learning: inter-national perspectives (pp. 106-126). Leicester, UK: National Institute of Adult continuing Education.

Portwood, D., \& Garnett, J. (2000). The construction and validation of an institutional Work Based Learning programme. In D. Portwood \& C. Costley (Eds.), Work Based Learning and the University: New perspectives and practices (SEDA Paper 109) (pp. 45-50). Birmingham, UK: Staff and Educational Development Association. Retrieved from https://eprints. mdx.ac.uk/2693/1/SEDA\%20Paper\%20Chapter\%20 Four\%20Portwood_Garnett\%20Split\%209.pdf

Quality Assurance Agency for HigherEducation. (2010, March). Institutional Audit: University of Chester. London, UK: QAA. Retrieved from http://www.qaa.ac.uk/ en/ReviewsAndReports/Documents/University\%20of\%20Chester/University-ofChester-IA-10.pdf

Robinson, E. (2007). 1966 and all that: A revolution in higher education that is yet incomplete. Higher Education Review, 39(3), 45-58.

Rogers, E. M. (2003). Diffusion of innovations (5th ed.). New York, NY: Free Press.

Rowe, L., Perrin, D., \& Wall, T. (2016). The chartered manager degree apprenticeship. Higher Education, Skills and Work-based Learning, 6(4), 357-369. doi:10.1108/ HESWBL-05-2016-0034

Singh, H. (2003). Building effective blended learning programs. Educational Technology, 43(6), 51-54. Retrieved from http://asianvu.com/digital-library/ elearning/blended-learning-by_Singh.pdf

Schmidt, R. (2006). DEWBLAM: The Social and Educational Challenge of Work Based Learning in European Higher Education and Training Results of a Pilot Experience. Florence: eform - Network per la formazione integrate.

Sutherland, J. (1998). Workplace learning for the twenty-first century: Report of the Workplace Learning Task Group. London, UK: Unison. 
Talbot, J., \& Leonard, D. (2009, April). Developing new work based learning pathways for housing practitioners whilst participating peripherally and legitimately: The situated learning of work based learning tutors. Paper presented at University Vocational Awards Council Annual Conference, University of Derby, Derby, UK. Retrieved from http://chesterrep.openrepository.com/cdr/bitstream/10034/86995/8/ talbot-derby\%20paper.pdf

Talbot, J., Perrin, D., \& Meakin, D. (2014). Risk management and cultural virtue in HE co-delivery arrangements. Quality Assurance in Education, 22(2), 109-124. doi:10.1108/QAE-12-2012-0047

Talbot, J. (2017a). In R. Nata (Ed.), Curriculum design for the post-industrial society: The facilitation of individually negotiated higher education in work based learning shell frameworks in the United Kingdom. In Progress in Education (vol. 44, pp. 127-161). New York: Nova Publications.

Talbot, J. (2017b). Repurposing MOOCs for the Accreditation of Prior Learning: A survey of practice in University Work Based Learning departments. Widening Participation and Lifelong Learning: the Journal of the Institute for Access Studies and the European Access Network, 19(3), 113-136. doi:10.5456/WPLL.19.3.113

UNESCO. (2012). UNESCO guidelines for the recognition, validation and accreditation of the outcomes of non-formal and informal learning. Hamburg, Germany: UNESCO. Retrieved from http://unesdoc.unesco.org/ images/0021/002163/216360e.pdf

WBLQUAL. (n.d.). Work Based Learning leading to Qualifications. Retrieved from http://wblqualv2.clients.apphaus.co.uk/home/

Werquin, P. (2010). Recognition of non-formal and informal learning: Country practices. Retrieved from: http://www.oecd.org/education/skills-beyondschool/44600408.pdf

Welsh, E., Wanberg, C., Brown, G., \& Simmering, M. (2003). E-learning: Emerging issues, empirical results and future directions. International Journal of Training and Development, 7(4), 245-258. doi:10.1046/j.1360-3736.2003.00184.x 


\section{KEY TERMS AND DEFINITIONS}

APCL (Accreditation of Prior Certificated Learning): A type of APL awarded on the basis that the student possesses credit from a prior award that is cognate with the planned WBIS program of study and award title. The prior award must be from an institution or organization of standing and the credit must be current - awarded within the past five years.

APEL (Accreditation of Prior Experiential Learning): A type of APL awarded on the basis of the demonstration of significant and appropriate learning from experience. The learning should be based upon significant and demonstrable professional practice given currency by means of reflective analysis, informed by relevant academic literature.

APL (Accreditation of Prior Learning): Use of accumulated academic credit for incorporation into a newly negotiated award. The maximum allowable APL on a named Chester award is two-thirds of the total credit.

ASLA (Approved Studies Learning Agreement): Learning contract and registration document combined, completed by students at the beginning of their studies on WBIS. The ASLA indicates their intended award title and planned program of studies along with completion dates. ASLAs are negotiated between individual stu-dents and their personal academic tutor (PAT) and then scrutinized by all WBIS tutors before being passed for registration purposes.

Co-Delivery: A process for accrediting learning in the workplace that involves cofacilitation and co-assessment with tutors otherwise employed in outside organizations, but who are mentored and trained to work with CWRS for these specific purposes.

CWRS (Centre for Work Related Studies): Centre within the faculty of business enterprise and lifelong learning for WBIS tutors.

External Examiners: Formal practice in U.K. universities for independently verifying quality assurance on all university programs of learning by means of the appointment of an independent academic as scrutineer and critical friend.

Higher Education Academy: U.K. body dedicated to improving the quality of teaching and learning in universities. WBIS tutors are all fellows of the HEA and participate in the specialist employer engagement network.

Higher Education Statistics Authority: UK government agency responsible for collating and publishing data on higher education. 
Learning From Experience Trust: Charitable foundation dedicated to facilitating the development and use of experiential learning. The trust was instrumental to establishing the changes in pedagogic practice that led to the creation of WBIS.

NELA (Negotiated Experiential Learning Agreement): Agreement between PAT and student as to the content and nature of a negotiated experiential learning module (NELM). A template is adapted indicating learning outcomes, focus, timescale, resources, and so on.

NELMs (Negotiated Experiential Learning Modules): Modules negotiated between PAT and student that al-lows for new experiential learning. NELMs are typically used to devise transdisciplinary workplace projects and can be either single (10 ECTS credits), double (20 ECTS) or triple (30 ECTS).

PAT (Personal Academic Tutor): WBIS tutor assigned to a student usually on the basis of personal expertise. For example, tutors with a health background are therefore likely to be a PAT for students working in the health sector. In addition to being responsible for welfare, progression, academic development and so on, the PAT also facilitates the Self-Review module, APL claims and NELMs.

Quality Assurance Agency: U.K. national body responsible for assuring the quality of higher education in the U.K. The QAA promotes good practice as well as carries out institutional inspections.

Shell Framework: Term used to describe a validated WBL program that enables learners to negotiate awards within a framework, without the need for further revalidation.

WAP (WBIS Approval Panel): University panel that meets regularly to assess the academic validity of pro-posed WBIS modules and specialist pathways within the WBIS framework.

Work-Based Learning: Term usually used to denote formally accredited experiential learning in the workplace with the emphasis on doing as an outcome.

Work-Related Learning: Term used to describe learning relevant to workplace practice that may not be experiential or focused on application. 


\section{ENDNOTES}

1 The Learning from Experience Trust (http://www.learningexperience.org.uk/ index.php) was established in 1986 by Norman Evans following time spent working at the Council for Adult and Experiential Learning in the 1970s (http://www.cael.org/). For a review of practices in respect to the assessment of experiential learning in England, see Pokorny (2011).

2 What is known as APL in the U.K. is referred to variously in other countries as Prior Learning.

Assessment (PLA- U.S. and Canada), Recognition of Prior Learning (RPLAustralia, South Africa, increasingly in the UK), Validation of Acquired Experience (VAE- France) or Validation of Non-formal and Informal Learning (VNIL- Germany, Spain). A 2012 European Council resolution recommended that European Union member states adopt the latter term, as well as implement strategies to capture such learning. It also is the term preferred by UNESCO (2012) and the Organisation for Economic Co-Operation and Development (OECD) (Werquin, 2010).

3 The U.K. National Qualifications Framework is aligned with the European Qualification Framework. It ascribes a level of learning for all qualifications from level 1 to level 8 . Level 4 is the standard achieved for the first year of a bachelor's degree, 5 the second year, 6 the final year. Level 7 is master's level. Level 8 is the doctoral level. 